\title{
O que significa infinitude formal? \\ Uma consideração das virtuosidades da concepção de música em Schopenhauer
}

\author{
What means formal Infinity? \\ A consideration of virtuositys of Schopenhauer Music's \\ Conception
}

\author{
Roberto de A. P. de Barros \\ Doutor do Filosofia pela universidade técnica de Berlin \\ Professor da Faculdade de Filosofia e do PPGFIL/UFPA. \\ Membro do grupo de sustentação do GT Nietzsche da ANPOF \\ E-mail: robertbarr@gmx.net
}

\begin{abstract}
Resumo: $O$ texto a seguir visa abordar aspectos que possibilitem uma compreensão ampla da interpretação schopenhaueriana da música. Isso, porém, partindo não apenas dos posicionamentos do autor sobre o tema, mas de um quadro geral de alguns aspectos decisivos para a concepção musical do século XIX. O objetivo prioritário é demonstrar a recepção de Schopenhauer destas temáticas, indicando a importância delas para os seus posicionamentos.
\end{abstract}

Palavras-chave: Música absoluta; Vontade; Keywords: Absolut music; Will; Effectivity
Abstract The following text aims to aboard broad aspects of Schopenhauer's interpretation of music. This, however, not only from the author's positions on the subject-matter, but from a general framework about decisive aspects for the musical conception of the nineteenth century. The primary objective is to demonstrate the reception of Schopenhauer these themes, indicating the importance of them for their positions. 
„Die Musik überhaupt ist die Melodie, zu der die Welt der Text ist“. Arthur Schopenhauer

discussão acerca das artes na Alemanha entre os séculos XVII e
XIX foi bastante marcada pela tentativa de aproximação da arte
alemã dos modelos clássicos norteados principalmente pela arte grega. Devido a isso, a poesia e a escultura ocupavam lugar central na discussão dos seus estetas. Esta perspectiva tem início no século XVII, com Winckelmann, é adaptada à visão cristã por Lessing e Herder e apenas vai ser claramente revista com Schiller e Goethe, que não mais se adequam a um simples venerar da tradição.

A intensão deste artigo é se aproximar da consideração de Schopenhauer da música a partir desta perspectiva, pois ela pressupõe uma interpretação da arte como mimesis, aspecto do qual a interpretação schopenhaueriana da música se afasta. Ao mobilizar estes aspectos busca-se diretamente tratar da separação efetuada por Schopenhauer entre a música e as demais artes, estas entendidas como imitações (Nachahmungen) de algum referente e a música, entendida como "representação daquilo que não pode ser representado".

Relacionado a isso, ocorre um outro aspecto significativo para esta abordagem, a relevância do ambiente musical do século XIX, decisivamente no que diz respeito ao surgimento da ideia de música absoluta, que se articula a um movimento de discussão estética teutônica que, todavia, tem como núcleo a poesia, a partir da separação da poética da retórica e da sua compreensão como arte autônoma ${ }^{1}$. No período, todavia, mesmo que norteado pela questão da naturalidade originária da manifestação poética de um povo - um tema central para os movimentos nacionalistas da época - era também central o tema da liberdade formal da poesia, que viria então a se expandir para a consideração da música.

Para tanto, é importante indicar um espectro argumentativo de certo modo amplo, mas eventualmente pertinente, a partir do qual desejo considerar os posicionamentos de Schopenhauer acerca da música. 1. O passo inicial será, então, uma consideração da alteração na concepção musical a partir do Barroco pósrenascentista, com a separação paulatina da música instrumental do canto e, em

1 RICHTER, S. A history of Poetics, p. 13. 
decorrência disso, com o surgimento do concerto e da teoria da música absoluta no século XVIII, quando a música deixa de ser vista como acompanhamento para a voz e passa a ser pensada como uma forma própria de linguagem. 2. Em seguida, será considerado o fato de que, por conta desta mesma tradição, o movimento de emancipação da música como arte particular é antecedido pela valorização do caráter específico da poesia no pré-romantismo e no romantismo, em uma tendência que veio a se refletir no domínio musical, para o qual - assim como para Schopenhauer - Beethoven é uma figura decisiva com respeito à superação do modelo pitagórico platônico de interpretação da música. 3. Por último, a partir destes pressupostos será considerada a interpretação da música em Schopenhauer a partir de outros três pontos centrais. 1. O seu estatuto para além das demais artes. 2. 0 seu afastamento da concepção mimética da arte e, finalmente, 3. Uma consideração das virtuosidades de sua interpretação da música a partir do seu caráter formal indeterminado.

\section{A música pós-renascentista}

A música ocidental foi fortemente marcada, por muitos séculos, pela concepção numérico-matemática da música elaborada por Pitágoras e reafirmada por Platão, fundada então na metrificação numérica de espaços e tons. Uma segunda via na antiguidade é a concepção aristotélica, sensualista, que adquiriria proveniência nos séculos iniciais do medievo. Por conseguinte, o padrão pitagóricoplatônico de consideração da música é marcado pela ideia desta como manifestação de números (métrica) e, portanto, como resultado de uma ressonância isomórfica e monofônica. Os pitagóricos conseguiram determinar os intervalos das oitavas em relações numéricas simples, de modo que a oitava expressa a relação 2:1, a quinta a proporção 3:2 e a quarta a proporção 4:3. Com a matematização do Cosmos, os pitagóricos formularam também a teoria da harmonia entre os planetas, que tanto interessaria a Platão no Timeu e a Aristóteles no De Coelo, em uma concepção musical e que é mencionada por Schopenhauer no tópico final do terceiro livro de $O$ mundo como vontade e representação (WWV/MVR). Platão e Aristóteles, apesar da diferença de suas concepções, assimilaram estas noções e as mobilizaram de forma diferenciada, todavia com um ponto em comum, o vínculo entre música e moral relacionada as ideias de equilíbrio e harmonia. 
Ainda segundo a interpretação grega da arte, esta é vista como atividade imitativa e educativa, de onde decorre também a concepção da poesia como a primeira forma de expressão universal. Esta concepção é originária de Aristóteles, para quem a poesia é mais filosófica que a história, pois ela comunica o geral

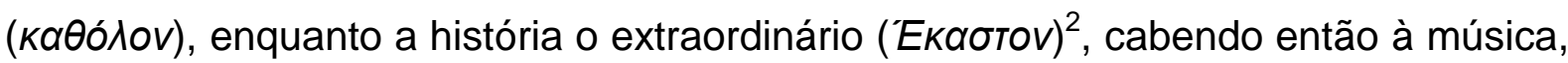
desde então a função de acompanhamento para a voz, seja na interpretação matemática pitagórico-platônica, que a concebia como ressonância isomórfica ${ }^{3}$, seja na interpretação sensualista de Aristóteles, para o qual a música é o terceiro elemento a ser ensinado às crianças, após as palavras e a ginástica, e que deve ser indicada como um elemento construtivo do repouso ${ }^{4}$. Apenas no cristianismo renascentista esta perspectiva será reconsiderada, em um distanciamento desta concepção de subordinação da música a uma finalidade associada à educação e à palavra.

Com efeito, estas noções consistem em objetos de estudos no ocidente a partir da obra de Boécio De instituitione musica, mantêm estabilidade nuclear na interpretação da música no ocidente e se mantém tematicamente central até o renascimento. Mesmo tendo uma concepção de música bastante distante da de Platão, tanto Giulio Caccini em seu La nuove musiche (1602), como os irmãos Monteverdi, Giulio Cezare e Cláudio (Scherzi Musicali, 1607), ainda enfatizam a primazia da palavra sobre a música ${ }^{5}$. Apenas após o renascimento uma teoria musical própria começou a ser formulada, tendo então dois pontos centrais de ruptura, o desenvolvimento matemático ${ }^{6}$ - já presente no neoplatonismo -, que possibilitava a ruptura com concepção de melodia a partir dos números racionais e de seus intervalos. Por outro lado, e quase que antagonicamente, a concepção de que uma interpretação matemática da música não poderia expressar a plenitude de seu significado, como, por exemplo, na enfática tematização desta perspectiva desde século IX, no escrito anônimo musica enchiriadis e ainda, posteriormente, na

\footnotetext{
2 ARISTOTELES. Poetik, p. 28.

3 BOND, M. E. Absolute Music, p. 39.

4 ARISTÓTELES. Política VIII, p. 378.

5 PALISCA, C. V.; MATHIESEN, T. J. Music and ideas in the sixtennth and seventeenth centuries, p. 5 .

6 Digno de nota o nome de Giovanni Battista Benedetti (1553 - 1590), componista amador, todavia pesquisador em acústica, que em 1585 publica o libro Diversarum specutationum mathematicarum et Physicarum liber, no qual se opõe a ideia da harmonia cósmica dos planetas, por achar ser possível não demonstrar proporções harmônicas no céu. Outros opositores da teoria da harmonia cósmica foram Leonardo da Vinci, Galileu Galilei e Kepler (PALISCA, C.
} V.; MATHIESEN, T. J. Music and ideas in the sixtennth and seventeenth centuries, p. 26). 
ideia mística de harmonia de Mauricio Ficino ${ }^{7}$. No século XVI o tema da afecção relativa a todas as artes já se encontra plenamente estabelecido ${ }^{8}$. Este último aspecto deixa à mostra as influências concepção da música como expressão não figurada, formal, mas que também, por meio do sentimento, possibilitava uma via de acesso à infinitude divina.

Por conseguinte, concomitantemente à influência universalizante da matemática e da geometria nas ciências naturais, dava-se no período pósrenascentista também a busca, no domínio das artes, pela linguagem universal. Neste sentido, no que se refere à relação entre palavra e ritmo, o recitativo é concepção central da música, do medievo ao barroco, passando, todavia, da polifonia para a concepção monofônica. A música barroca, com a camerata florentina, em sua tentativa de romper com o canto gregoriano medieval e com a polifonia renascentista, buscava recriar o estilo dos dramas gregos antigos, ainda estabelecia o discurso como aspecto mais importante. Aspectos de grande significação eram a busca de alternativas para a monofonia tonal da música medieval e para a incompreensibilidade do discurso na perspectiva polifônica. Disso surgiu o recitativo cantado, caracterizado por uma melodia emotiva, quase mais declarada que cantada e com um acompanhamento instrumental em segundo plano.

Por conseguinte, a música barroca ainda tinha como meta a ideia tradicional advinda de Aristóteles $^{9}$, de expressar a multiplicidade das tonalidades da voz humana (afetos), tentando manifesta-las, porém, em formas definidas e fixas. 0 incremento do baixo contínuo, na fase inicial do Barroco, por conseguinte a opção pela maior clareza da monofonia e da música instrumental em desfavor da música vocal polifônica são alguns fatores decisivos para as mudanças musicais e teóricas com respeito a música no século XIX.

Esta inovação chega à Alemanha por meio de Henrich Schütz, que após seus primeiros estudos na Itália em 1613 retorna a Dresden, onde começa a compor os seus expressivos oratórios. Desse processo, além do oratório, fuga, sonata e cantata, resulta o concerto (concerto grosso), caracterizado pela alternância entre

\footnotetext{
7 ALBERTINI, Mauricio Ficcino, p. 80.

8 PALISCA, C. V.; MATHIESEN, T. J. Music and ideas in the sixtennth and seventeenth centuries, p. 12.

9 Seguindo Aristóteles, alemães do século XVI como Nikolaus Listesius em seu Rudimenta Musicae Planae (Wittemberg, 1533), ou Heinrich Faber (Musica Poetica,1548), Joachim Burmeister e Johann Andreas Herbst criam a designação Música teorética, afastando-se assim da divisão tradicional relacionada ao Trivium e ao Quadrívium entre Musica pratica e Musica poética, que pressupunha a relação entre música e arte retórica. Neste novo uso, palavra poética, todavia, se refere a poieis, produção, fabricação e não à arte da poesia, e dá origem à separação da música em Sortitatio - da qual decorre a música campesina italiana (Villanellen), o cântico rústico (cantica rustica) religioso, o Barenlieder - e o compositio, do qual advém o contraponto.
} 
grupos de solistas (posteriormente substituídos por um único solista) e orquestra. Schütz adapta então a melodia ao ritmo da língua alemã, o que manteria o oratório popular em domínios desta até o século XVII, concomitantemente ao crescimento pelo interesse germânico pela ópera.

O distanciamento se torna mais nítido com a necessidade de clareza do classicismo e o estabelecimento da sonata e da sinfonia, que então se separa mais claramente das óperas e oratórios. Surge então a ideia da música absoluta, autônoma e auto-referencial, que constitui um tema central para a estética musical da primeira metade do século XIX. A importância desta temática pode ser percebida na crítica de Richard Wagner no seu texto de 1846 Programm zur 9. Sinphonie von Beethoven, no qual Wagner tende a compreender o termo criticamente, como contraposto a sua ideia de uma Gesammtkunstwerk, por conseguinte como um isolamento da música.

\section{A questão do status da poesia para o pré-romantismo alemão e a emancipação da música}

Desde o século XVII, com Winckelmann, os gregos foram tomados pelos alemães como modelos a serem seguidos e copiados, enquanto arquétipos para a formulação de uma concepção de cultura elevada, caracterizada pela naturalidade e pela idealidade ${ }^{10}$. Desta tendência, resultou um forte anseio por uma compreensão originária dos helenos, a partir do estabelecimento de clara diferenciação entre eles e às culturas alexandrina e romana. Mesmo que de modo multifacetado, a via de consideração iniciada por Winckelmann percorre toda a reflexão alemã acerca dos gregos e da arte. A inclinação moral do interesse pelos gregos e pela sua arte pode ser evidenciada na interpretação de Winckelmann do Laocoonte, para ele produto da perspectiva do equilíbrio das emoções e sentimentos, que Winckelmann identifica como nobre simplicidade e grandeza serena (Edle Einfalt und eine stille Grösse) ${ }^{11}$. Mas a tendência, que Winckelmann tão emblematicamente inicia e identifica, origina, dois movimentos concernentes à interpretação dos gregos. A primeira variante, de

10 WINKELMANN, J. J. Gedanken über die Nachahmung der griechischen Werk in der Malerei und Bildhauerkunst, p. 13

11 Idem, p. 20.

O que significa infinitude formal? Uma consideração das virtuosidades da concepção de música em Schopenhauer 
valorização dos helenos é o neoclassissismo, que viria a aferir marca indelével à filologia germânica, influenciada inicialmente pelo luteranismo ${ }^{12}$ e pela interpretação das Escrituras, já se encontra estabelecida na Alemanha de Baumgarten ${ }^{13}$ e Wolf. Esta encaminha-se, decididamente, a partir do romantismo, para um esforço em buscar uma interpretação purista da língua alemã, a partir do pressuposto da originalidade da língua grega. A segunda tendência, a filosófico-artística, romântica, busca encontrar dados da singularidade helênica não apenas em fatores históricos, geográficos e políticos, mas também em suas qualidades inerentes, a partir de uma interpretação naturalista ${ }^{14}$ dos gregos. Esta tendência, que apesar de igualmente ter em Winckelmann seu principal precursor ${ }^{15}$, pode ser estendida, ainda que de forma ainda que dispare, a Lessing, Herder, Goethe, Schiller e Hölderlin. Os três últimos podem ser caracterizados como grandes expoentes de uma corrente de interpretação naturalista da arte grega, que buscou se afastar dos formalismos e modismos modernos, fundamentalmente do classicismo francês, objetando com isso identificar uma forma natural de manifestação artística. Goethe e Schiller oscilam entre críticas direcionadas às artes francesas e influências gregas, sendo que, este último, pode ser visto já como voltado à problematização do modo de se interpretar os helenos, o que o leva, de modo bastante particular, a até mesmo a afirmar a superioridade dos modernos sobre os antigos ${ }^{16}$. Goethe associa o espírito evoluído com a alta erudição da época e não se deixa restringir pela mera cópia dos antigos, mas pensa na assimilação de seus princípios como forma de impulsionar um impulso criativo ${ }^{17}$.

Se considerado o texto de August Wilhelm Schlegel Cartas sobre a poesia, métrica e linguagem (Briefe über die Poesie, Silbenmass und Sprache), de 1795, como expressão da discussão acerca da natureza da poesia no pré-romantismo alemão, é possível indicar o esforço de vários autores de romper com a tradição que aproximava e poesia da retórica, tal como ela se apresenta desde a idade média no Trívium. A separação da fala poética da sua consideração formal e do uso convencional da linguagem é uma tendência que se inicia no século XVII e alcança

12 BRITTO, F. L. Lutero e a intenção da tradução erudita alemã, p. 12.

13 MATTOS, C. V. Winckelmann e o meio antiquário de seu tempo, p. 76.

14 Utilizo aqui essa designação no sentido segundo o qual Rudolf Steiner se refere à arte grega, como: "uma extensão do viver e atuar dentro da natureza". Cf. STEINER, G. Arte e estética segundo Goethe, p, 13.

15 SÜSSEKIND. P. Schiller e os gregos, p. 76.

16 Idem, p. 168.

17 GOETHE, J. W. Escritos sobre arte, 233.

O que significa infinitude formal? Uma consideração das virtuosidades da concepção de música em Schopenhauer 
claramente o século $\mathrm{XIX}^{18}$, todavia, em um sentido ambivalente, que exprimia tanto a necessidade do estabelecimento positivo da poesia, como uma consideração negativa desta, devido aos excessos metafóricos ${ }^{19}$. A consideração destes excessos expressava o espírito do tempo, marcado pela ciência e pela percepção, desde Galileu, ponto de partida de Kant, de que o intelecto humano apenas se ocupa com aquilo que ele mesmo produz e que, por conseguinte, muito embora as explicações científicas devam necessariamente prover uma explicação do real, estas não produzem uma imagem, uma cópia da natureza, mas um modelo desta ${ }^{20}$, expressão da sua verdadeira realidade objetiva não imediatamente evidente.

Em sua origem moderna, a aspiração de se produzir uma representação matemática da estrutura mais elementar do mundo é extremamente otimista. Este sentimento que dominaria os séculos XVII e XVIII se altera no século XIX. Neste momento, um modelo muito mais dinâmico de interpretação seria amplamente proposto nas ciências no período, mais especificamente no que diz respeito à substituição da matéria por campos de forças, que se impunham como verdade última $^{21}$. Mas a ampliação do aparato matemático e da necessidade de calcular grandezas não mais a partir de números reais já é uma concepção do século XVIII e a música não ficou distante dos efeitos causados por estas mudanças.

Precisamente devido a matemática, alterou-se o status da música, que teria então reconhecida a sua amplitude formal e o seu traço universal. Até então, dado o conteúdo moral da discussão acerca da arte presente no pensamento ocidental desde Platão e que perpassa toda a interpretação da arte como mímesis, a música fora vista até então como uma arte secundária, de acompanhamento das artes figurativas ou imageticamente objectantes. No século XVIII, a percepção das dificuldades de uma aplicação universal do modelo mecanicista remete a concepções menos lineares de interpretação do mundo. Na música as noções de gênio, de originalidade e de expressão individual começam a suplantar a ideia de imitação $^{22}$. O classicismo vienense, de Haydn, Mozart e posteriormente de Beethoven, reforçam esta ideia. Com efeito, Beethoven é o primeiro compositor

18 RICHTER, S. op. cit., p. 11.

19 Idem., p. 12.

20 LAUXTERMANN, P. F. Schopenhauer's broken world-view, p. 20.

21 HEISENBERG, W. A imagem da natureza na física moderna, p. 12.

22 BOND, M. E. op. cit., p. 105.

O que significa infinitude formal? Uma consideração das virtuosidades da concepção de música em Schopenhauer 
independente da história da música europeia e que encorpa tanto a ideia de singularidade quanto a de liberdade do gênio. Em 1800, Herder já afirma a música como livre em seu estado inicial, precedendo até mesmo a linguagem. Dez anos depois, E. T. A. Hoffmann, em seu escrito sobre a 5a Sinfonia de Beethoven, enfatiza diretamente a natureza da música, que ele interpreta apenas como passível de ser expressa na música instrumental ${ }^{23}$. Surgia então, no século XVIII a diferenciação entre música pura e aplicada, que trariam consigo as ideias de autonomia estética e moral da música.

\section{A concepção schopenhaueriana}

Obviamente não seria possível, e nem mesmo exequível, tentar contar uma história da estética musical concernente a este tema, mesmo ainda que restrita aos domínios da problematização alemã. Neste sentido, se recorrerá a determinadas fontes e aspectos que podem possibilitar uma referência defensável deste tema. $O$ ponto de partida adotado aqui, que não é novo, se baseia no princípio de que é possível argumentar que a posição inovadora de Schopenhauer com respeito a música se deve a uma reconsideração da teoria kantiana do sublime e que essa o remete a uma valorização da percepção intuitiva e a uma desvinculação da imagem como aspecto positivo ${ }^{24}$, isso em favor das formas fluidas do sentimento. Isso pensado no sentido de uma diferenciação da consideração kantiana da música, segundo o mais que conhecido entendimento desta na terceira crítica, segundo o qual ela é preterida em favor das artes plásticas ${ }^{25}$.

Neste sentido, dois aspectos decisivos, resultantes da filosofia kantiana e assimilados por Schopenhauer devem ser mencionados. 1. A percepção da limitação da capacidade representativa das faculdades humanas no que se refere a ordem objetiva das coisas. 2. O ultrapassamento da limitação conceitual (ideal) na experiência estética do sublime e, assim, da percepção intuitiva da coisa em si. Com efeito, o primeiro ponto pode ser resumido na acepção da assimilação de grande parte dos posicionamentos de Kant apresentados na estética transcendental da Crítica da razão pura. Com relação ao segundo ponto, a partir da consideração do

23 Idem., p. 106

24 CACCIOLA, M. L. Sobre o Gênio na estética de Schopenhauer, p. 32.

25 KANT, I. Critica da faculdade do juízo § 53, p. 174 
sentimento do sublime no $\S 39$ de MVR, deve ser, todavia, acentuada a alteração que Schopenhauer efetua na sua compreensão, ou seja, diferentemente de Kant, a interiorização deste sentimento a partir da sua própria experiência, então não do exterior, mas do interior da cena. Esta experiência estética é reproduzida com a música e está presente na própria estrutura da mesma, na conciliação das tenções harmônicas e desarmônicas, que Schopenhauer identifica na obra de Beethoven, independentemente de sua preferência por Rossini e Mozart ${ }^{26}$. A música, por conseguinte, oferece, ainda que intuitivamente, um preciosíssimo instrumento de superação das limitações indicadas pela filosofia kantiana com respeito à coisa em si, haja visto ser a experiência estética a única forma de superar a estrutura lógica de nossas intuições representativas e, neste sentido, a música demonstra a sua superioridade com respeito às demais artes.

Estes aspectos são significativos, pois remetem diretamente à questão de experiência musical, considerado que a música deve ser experimentada, mas ao mesmo tempo ela nos emociona fortemente (entsetzt) e isso poderia nos afastar da pretensão de aniquilação da vontade de viver. Schopenhauer busca superar essa posição paradoxal com a noção de elevação pelo pavor (Schreck), que a música de forma privilegiada nos possibilita, por ser ela aquela que melhor representa a os conflitos de forças da natureza e assim nos possibilita intuí-lo. Isso se dá, porque Schopenhauer parece precisar do sublime enquanto experiência imanente, afastando-se assim de Kant, que o mobiliza como ideia ${ }^{27}$.

Os posicionamentos mais gerais de Schopenhauer acerca da arte são conhecidos. Partindo de sua hierarquização das artes a partir da gradação da maior à menor referência dos graus de objetivação da vontade, sua análise do gênio e da experiência artística o leva a afirmar o estado estético como intuição não subjetiva das ideias, entendidas como as mais perfeitas formas de objetivação da vontade ${ }^{28}$. Assim como o conhecimento racional, todavia de uma forma decisivamente outra, a arte fornece uma representação intuitiva dos princípios universais das coisas submetidas ao princípio de razão. Ela é o conhecimento intuitivo que examina o exterior independentemente de toda relação, buscando, porém, expressar o seu verdadeiro conteúdo que, então, é expresso pela ideia, a objetividade imediata e 
adequada da coisa em $\mathrm{si}^{29}$.

A contemplação artística leva à superação do princípio de individuação e da subordinação à vontade e então remete ao puro sujeito do conhecimento ${ }^{30}$. Nele ocorre a perda da proeminência da consciência empírica e disso resulta a compreensão da arte como via de superação do princípio de razão e do arrefecimento do sofrimento pelo conhecimento da ideia, entendida como objetividade imediata e adequada da coisa em $\mathrm{si}^{31}$. Neste sentido, as artes são consideradas por Schopenhauer a partir de seu grau de objetivação, da arquitetura à poesia trágica elas são consideradas a partir do grau de objetivação da ideia, da objetividade adequada da vontade, o que cria uma tenção entre a vontade que quer e ela mesma, ao querer não querer o querer o mundo. Desse modo, a vontade busca produzir formas mais estáveis e isso só é possível por meio das construções humanas mais elevadas, a arte e o conceito.

A música, todavia, é tomada por Schopenhauer como uma arte completamente diferenciada (ganz abgesondert) das demais, pois nela não podem "ser reconhecidas nenhuma cópia, repetição de alguma ideia de ser no mundo"32 e, desse modo, em muito mais ampla dimensão ela aproximar-se dos infinitos graus de objetivação da vontade, ficando a figuração apenas a cabo do ouvinte por meio da fantasia. Diferentemente das demais artes, a música deve então ser apartada da ideia de imitação, pois em sua amplitude formal ela não representa nenhum objeto específico $^{33}$, mas sim a possibilidade formal de toda representação e, neste sentido, ela pode ser compreendida como a expressão mais fiel da própria vontade, indefinível ou irrepresentável segundo critérios estéticos, mas passível de ser intuída pela experiência interna causada pela música.

Essa é a forma de reprodução do mundo efetuada pela música. A forma de aproximação de ambos é oculta, pois a música é a representação daquilo que não pode ser representado e por isso ela á a pode ser vista também como um modelo de representação que busca expressar a objetivação imediata da vontade, todavia não como objeto, mas em sua infinitude de formas. Desse modo, a música é a mais genuína e pura intuição formal ilimitada da vontade, compreendida também como 
indeterminável ${ }^{34}$. Ela possibilita a intuição mais simples, todavia mais geral, não figurativa, daquela. Ela é imitação intuitiva apenas da infinitude formal, um abstractum da efetividade (ein Abstracktum der Wirklichkeit) ${ }^{35}$, através do qual é possível a aproximação da própria essência do mundo, não por meio do conceito, mas da pura intuição artística.

Estes posicionamentos se confirmam nos suplementos escritos a sua obra capital. Como conclusão eu gostaria de rapidamente mencionar algumas passagens do textos complementares ao terceiro livro de MVR, prioritariamente o capítulo XXXIX intitulado "sobre a metafísica da música", no qual Schopenhauer dá mostras não apenas da atenção e do conhecimento da importância da compreensão das mudanças estruturais da concepção musical até os seus dias, como em diversas passagens indica o seu afastamento da ideia de música como acompanhamento da poesia $^{36}$, asseverando com isso até mesmo a precedência desta com respeito à primeira, ao afirmar que "as palavras são e permanecem como acréscimos estrangeiros de valor secundário para a música" ${ }^{37}$. Os temas da música "puramente instrumental" e da dissonância se fazem significativamente presentes neste texto e são associados a Beethoven e relacionada a ideia de uma "maior confusão" da música, mas que redunda em uma bela harmonia final e a música considerada como "um meio de tornar inteligível relações numéricas racionais e irracionais"38. Schopenhauer dá mostras de que esta confusão resulta da alteração dos pressupostos tradicionais da harmonia fundada na ideia da relação racional entre os tons, nos quais os intervalos, os semitons ou dissonâncias eram vistos como não harmônicos ou irracionais. A ampliação da matriz matemática de consideração da música permite esta alteração, portanto a mudança da tônica da música do século XIX, em claro afastamento da harmonia concebida anteriormente. Todavia, o que Schopenhauer elogia como infinitude formal da música enquanto expressão da vontade não é o seu formalismo, mas a sua amplitude perceptiva, pois embora ela seja um meio de inteligibilidade, com esse elemento a música se torna:

34 ABBATINO, L. Ich, Schopenhauer bleibe Mozart und Rossini treu, p. 300. 35 SCHOPENHAUER, A. WWV I/MVR I, § 52.

36 SCHOPENHAUER, A. WWV II/MVR II, p. 130.

37 Idem, p. 131.

38 Idem, p. 134.

O que significa infinitude formal? Uma consideração das virtuosidades da concepção de música em Schopenhauer 
O material pelo qual todos os movimentos do coração humano, ou seja, da vontade, movimentos cuja natureza essencial é sempre a satisfação e a insatisfação, embora em graus inumeráveis, podem ser retratados e fielmente reproduzidos em todos os seus mais delicados matizes e modificações, e isso se dá por meio da invenção da melodia ${ }^{39}$.

A música possibilita então uma percepção infinitamente ampla, todavia intuitiva, da essência do mundo. A "história secreta de nossa vontade e de todas as suas agitações e esforços", mas que revela, dentre outras coisas, a limitação do formalismo na sua representação e a proficuidade da assimilação desta amplitude formal para se compreender o mundo em sua imanência.

Abstraída a conotação metafísica destes posicionamentos, os seus desdobramentos e efeitos adquirem grande relevância, significativamente quando pensados os modelos dinâmicos de interpretação da efetividade que se fariam presentes na filosofia no século seguinte ${ }^{40}$. Isto não apenas no que tange questões estéticas, mas também epistemológicas ${ }^{41}$. Todavia, o que deve ser feita, é a clara indicação de que, deste modo, Schopenhauer dá um passo significativo no sentido de constituir-se em um efetivo ponto de inflexão do pensamento ocidental, decisivamente no que se refere à assimilação da necessidade de uma matriz dinâmica de interpretação do mundo.

\section{Referências bibliográficas}

ABBATINO, L. Ich, Schopenhauer bleibe Mozart und Rossini treu. In: Koßler, M. (Org). Musik als Wille und Welt. Würzburg: Königshausen und Neumann, 2011.

ALBERTINI, T. Mauricio Ficino: Das Problem von Denken und Welt in einer Metaphysik der Einfachheit. Wilhhelm Fink Verlag, 1997.

ARISTÓTELES. Poetik. Stuttgart: Philipp Reclam, 2010. Politik. Stuttgart: Philipp Reclam, 2013.

BARBOZA, J. A metafísica do Belo de Arthur Schopenhauer. São Paulo: Humanitas, 2001. BOND, M. E. Absolute Music. 2014.

BRITTO, F. L. de. Lutero e a intenção da tradução erudita alemã. Revista Índice [http://www.revistaindice.com.br], vol. 01, n. 01, 2009/ 2, p 49-67.

CACCIOLA, M. L. Sobre o gênio na estética de Schopenhauer. Florianópolis: Ethic@, vol. 11, n. 2, pp. 31-42.

GILLIPSIE, C. The Edge of Objectivity. New Jersey: Princeton University Press, 1990.

GOETHE, J. W. Escritos sobre arte. Tradução brasileira de Marco Aurélio Werle. São Paulo: Humanitas Imprensa oficial, 2008.

39 Idem, p. 134

40 GILLIPSIE, C. The Edge of Objekivity, p. 495.

41 WUCHTERL, K. Die Struktur philosophischer Revolutionen und die Gegenwart der Philosophie, p. 270. 
HEISENBERG, W. A imagem da natureza na física moderna. Lisboa: Livros do Brasil, sd. KANT, I. Crítica da razão pura. Lisboa: Fundação Caloustre Gulbenkian, 2001. . Crítica da Faculdade do juízo. Tradução de Valério Rohden e António Marques. $2^{a}$ edição. Rio de Janeiro: Forense Universitária, 2002.

LAUXTERMANN, P. F. Schopenhauer's broken world-view. Colours and Ethics between Kant and Goethe. Dorbrecht: Springer, 2000.

LÜTKEHAUS, L. Die Welt als Wille und Musik. Arthur Schopenhauer Musiksphilosophie. In: Koßler, M. (Org). Musik als Wille und Welt. Würzburg: Königshausen und Neumann, 2011.

MATTOS, C. V. Winckelmann e o meio antiquário de seu tempo. Revista de história da arte e Arqueologia, 9, 2008. 69-79.

SCHOPENHAUER, A. Werksausgabe. Zürich: Haffmans Verlag, 1987. . O mundo como vontade e como representação. Tradução brasileira de Jair Barboza. São Paulo: Editora UNESP, 2005.

O mundo como vontade e representação. Tomo II. Tradução brasileira de Eduardo Ribeiro da Fonseca. Curitiba: Editora UFPR, 2014.

PALISCA, C. V.; MATHIESEN, T. J. Music and ideas in the sixtennth and seventeenth centuries. Illnois: University of Illinois, 2006.

RICHTER, S. A history of Poetics. German scholarly aesthetics and poetics in international context, 1770-1960 / by Sandra Richter; with bibliographies by Anja Zenk ... [et al.].

STEINER, G. Arte e estética segundo Goethe. Tradução brasileira de Marcelo da Veiga Gruel. São Paulo: Antroposófica, 1998.

SÜSSKIND, P. Schiller e os gregos. Revista Kriterion, Belo horizonte, n. 112, Dez/2005, pp. 243-259. $\overline{67-77 .}$

A Grécia de Winckelmann. Revista Kriterion, Belo Horizonte, no 117, Jun./2008, pp.

WERLE, M. A. Winckelmann, Lessing e Herder: Estética do efeito? Trans/form/ação, 23: São Paulo: UNESP, 2000, pp. 19-50.

WINCKELMANN, J. J. Gedanken über die Nachahmung der griechischen Werk in der Malerei und Bildhauerkunst. Stuttgart: Philipp Reclam, 1969.

WUCHTERL, K. Die Struktur philosophischer Revolutionen und die Gegenwart der Philosophie. In: Stachowiak, H, Modelle - Konstruktion der Wirklichkeit. Frankfurt am Main: Fink Verlag, 1983, p. $239-282$. 